US Army Corps of Engineers ${ }_{\circledast}$

Engineer Research and

Development Center

Navigation System Research Program

\title{
Investigating the USACE Operational Condition Assessment Process Current and Future
}

Willie H. Brown and Jonathan K. Alt

March 2021

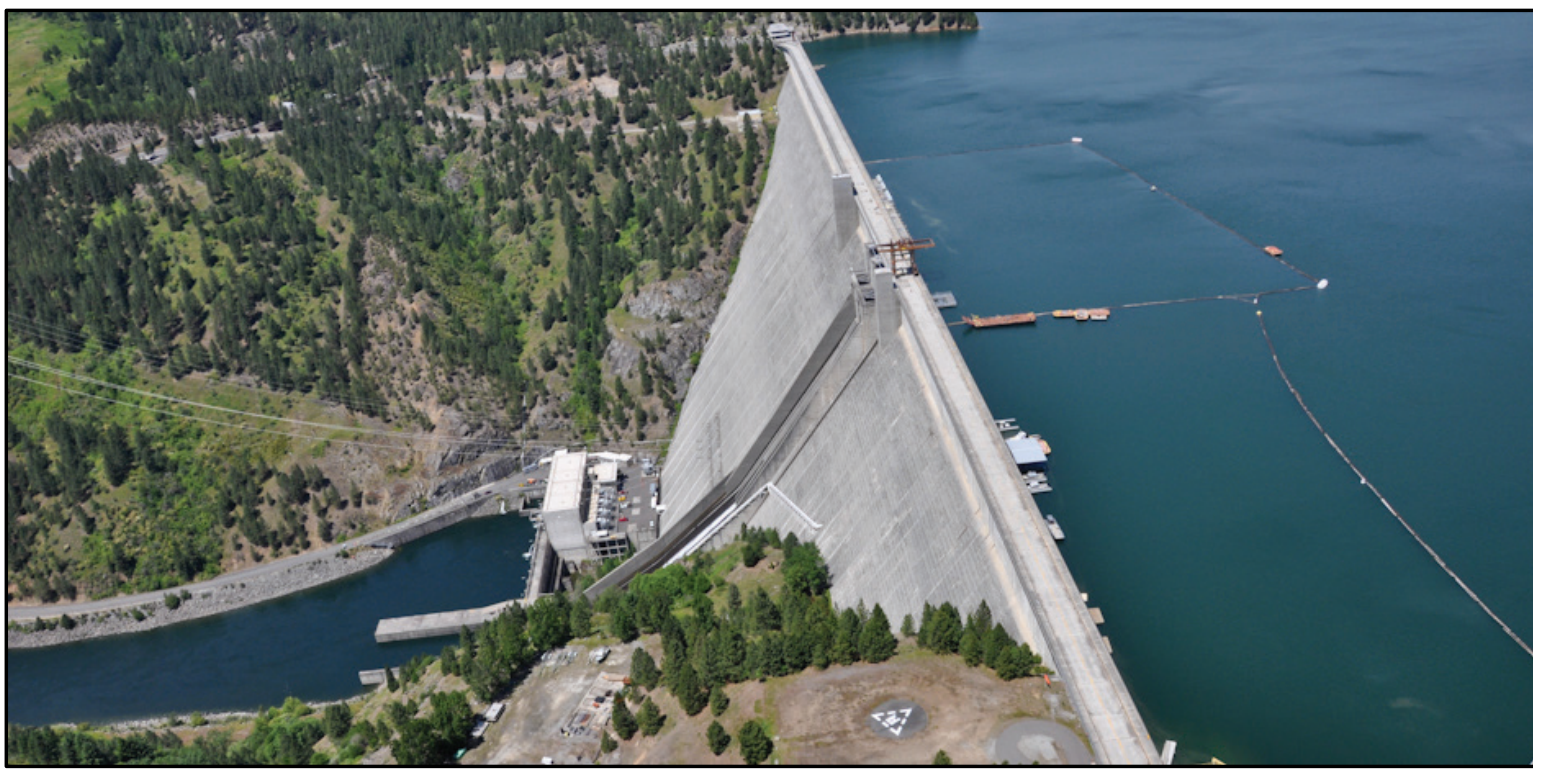


The US Army Engineer Research and Development Center (ERDC) solves the nation's toughest engineering and environmental challenges. ERDC develops innovative solutions in civil and military engineering, geospatial sciences, water resources, and environmental sciences for the Army, the Department of Defense, civilian agencies, and our nation's public good. Find out more at www.erdc.usace.army.mil.

To search for other technical reports published by ERDC, visit the ERDC online library at https://erdclibrary.on.worldcat.org/discovery. 


\section{Investigating the USACE Operational Condition Assessment Process Current and Future}

Willie H. Brown and Jonathan K. Alt

Information Technology Laboratory

US Army Engineer Research and Development Center

3909 Halls Ferry Road

Vicksburg, MS 39180-6199

Final report

Approved for public release; distribution is unlimited.

Prepared for Navigation Systems Research Program

Coastal Hydraulics Laboratory

US Army Engineer Research and Development Center

Vicksburg, MS 39180-6199

Under Funding Account Code U4371811; AMSCO Code 031391 


\section{Abstract}

The US Army Corps of Engineers operates, maintains, and manages more than $\$ 232$ billion worth of the Nation's water resource infrastructure and relies on the Operational Condition Assessment (OCA) process to determine the condition of the assets and their components. The sheer number of components, all of equal OCA scheduling priority, creates challenges in ensuring that assessments are conducted in a timely manner and that data generated are of sufficient quality to inform resource allocation decisions. This research applied methods from systems design to determine the OCA system "as-is" state and create a stakeholder-informed vision of a "to-be" state that addresses current system challenges. To meet its objective of providing current assessments of asset condition, the OCA system must provide four high-level functions: provide access to asset data, conduct assessments, determine asset risk, and prioritize and schedule assessments. The development of capabilities to provide these functions will facilitate the achievement of the OCA system to-be vision: a consistent view of asset condition and risk across the enterprise.

DISCLAIMER: The contents of this report are not to be used for advertising, publication, or promotional purposes. Citation of trade names does not constitute an official endorsement or approval of the use of such commercial products. All product names and trademarks cited are the property of their respective owners. The findings of this report are not to be construed as an official Department of the Army position unless so designated by other authorized documents. 


\section{Contents}

Abstract............................................................................................................................ if

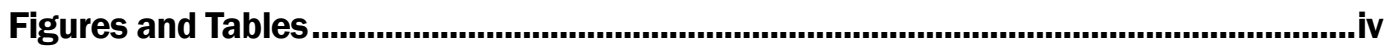

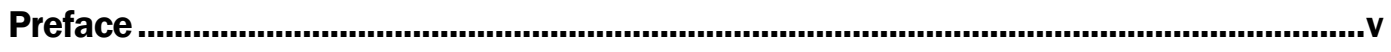

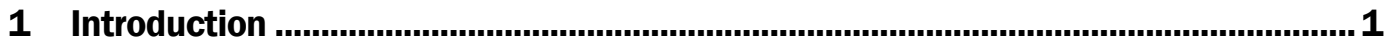

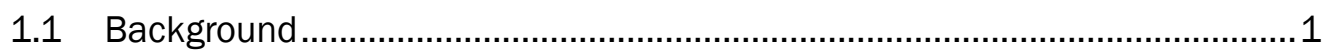

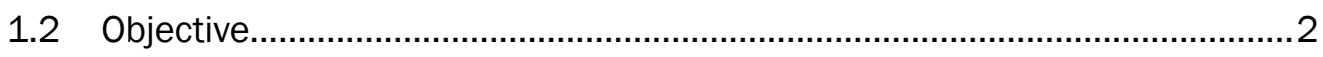

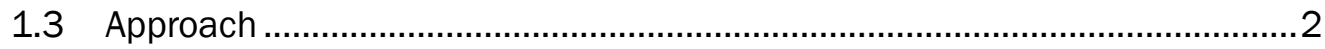

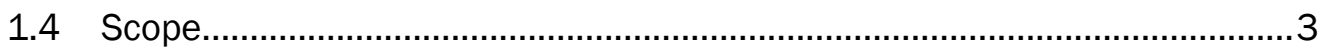

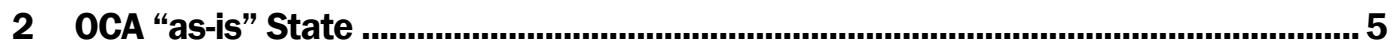

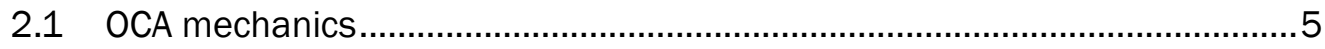

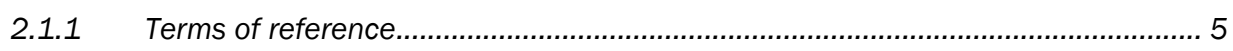

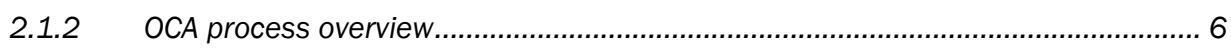

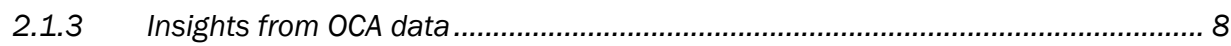

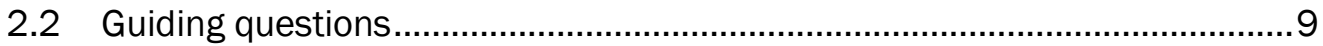

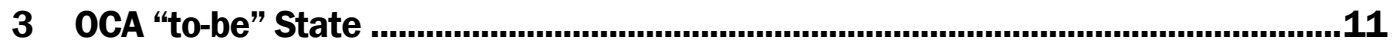

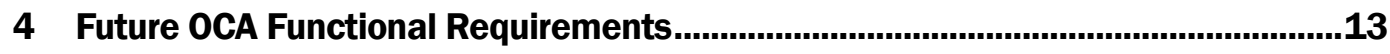

4.1 Strategic objectives to achieve modernized OCA .................................... 13

4.2 Determining operating project risk, FY21-23 ....................................... 13

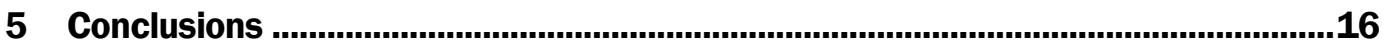

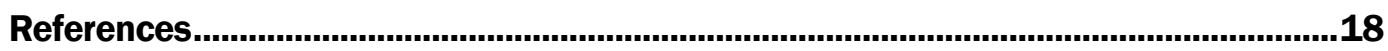

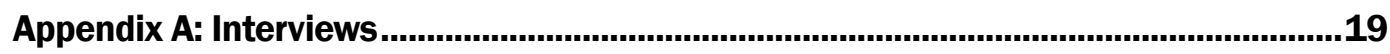

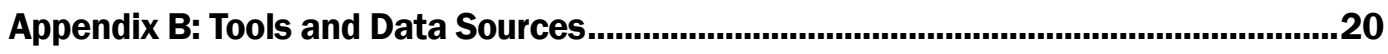

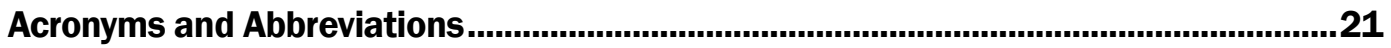

Report Documentation Page 


\section{Figures and Tables}

Figures

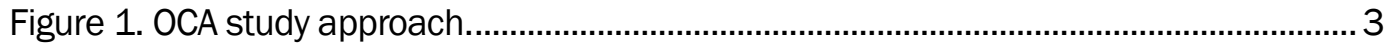

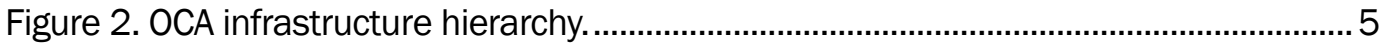

Figure 3. Sardis Dam OCA decomposition. ...................................................................... 8

Figure 4. Sardis Dam example system, subsystem, and components. ............................... 8

Figure 5. OCA impact on CW resource allocation............................................................10

Figure 6. High-level OCA system functional decomposition..............................................11

Figure 7. Determining likelihood of failure based on component condition........................14

Figure 8. Determining FRM risk...................................................................................15

\section{Tables}

Table 1. OCA rating scale and definitions (USACE 2019)................................................... 7

Table 2. The stakeholder interviews that informed the "as-is" and "to-be" states.............19 


\section{Preface}

This study was conducted for the Navigation Systems Research Program, Coastal Hydraulics Laboratory, US Army Engineer Research and Development Center, under Funding Account Code U4371811; AMSCO Code 031391. Ms. Morgan Johnston was the Program Manager for the Navigation Systems Research Program, and Mr. Peter Dodgion was the Program Manager for Asset Management, Headquarters, USACE.

The work was performed by the Institute for Systems Engineering Research (ISER), Computational Science and Engineering Division, Information Technology Laboratory (ITL), US Army Engineer Research and Development Center (ERDC), and the Hydrologic Systems Branch, Flood and Storm Protection Division, ERDC Coastal and Hydraulics Laboratory. At the time of publication of this report, Dr. Simon R. Goerger was ITL ISER Director; Dr. Jerry Ballard was ITL Computational Science and Engineering Division Chief; and Dr. Robert Wallace was the ERDCITL Technical Director for Engineered Resilient Systems. The Deputy Director of ERDC-ITL was Ms. Patti Duett, and the Director of ERDC-ITL was Dr. David Horner.

COL Teresa A. Schlosser was the Commander of ERDC, and the Director of ERDC was Dr. David W. Pittman. 


\section{Introduction}

\subsection{Background}

The US Army Corps of Engineers (USACE) operates, maintains, and manages more than $\$ 232$ billion worth of the Nation's water resource assets - impacting American citizens on a daily basis. This infrastructure is declining in condition and functionality as it ages and receives less than optimal care. USACE uses an Operational Conditional Assessment (OCA) process to prioritize maintenance and repair of these structures. Condition is defined in terms of impact to performance, operation, or maintenance as well as the potential for failure, where failure is defined as loss of function. The OCA currently defines the impacts from condition in vague terms (e.g., "advanced state of degradation," "potential to cause a functional failure," "moderately affects," and "substantially affects"). Although additional guidance is given for specific defects, inspectors interpret the terminology and apply them differently, leading to a variation in condition ratings and an inherently unreliable assessment system ${ }^{1}$.

Additionally, the proper determination of condition is a function of the depth of inspection (e.g., level of access provided, use of tools, and nondestructive testing length of time spent inspecting) and the experience of the inspector (e.g., understanding system behavior as well as knowing where and how to look for defects). This often results in an inconsistent application of ratings. The USACE also conducts OCAs on all components at each operating project with no prioritization of components based on their criticality to the system's operation. The sheer number of components across the enterprise and qualitative nature of the assessments result in late identification of issues and a lack of confidence in the assessment process. The USACE Asset Management (AM) program seeks a greater understanding of the current state of the OCA process and its effectiveness in order to identify opportunities to improve the process through focused modernization efforts.

\footnotetext{
1 Sauser, P. Unpublished. Statement of Need: Increasing the Reliability of Condition Data Collection for Operational Condition Assessments of Hydraulic Structures.
} 


\subsection{Objective}

This study investigates the current state of the OCA process and envisions a potential future state. The team worked with stakeholders and arrived at the following problem statement:

To develop a roadmap for the modernization of the OCA process to improve the quality and timeliness of data generated by the assessment process and used to make resource allocation decisions to ensure risk associated with critical infrastructure assets is mitigated.

The following two questions guided this work:

- What is the current state of the OCA process ("as-is" state)?

- What opportunities exist to improve the OCA process ("to-be" state) through modernization?

\subsection{Approach}

This study consists of a literature review of the OCA process, stakeholder interviews (Appendix A) (Table 2), and gathering various data sources (Appendix B). A literature review of relevant USACE literature yielded a general understanding of the mechanics of the OCA process. Then, to understand the process in greater detail, the researchers interviewed 13 people from six different USACE organizations: Asset Management (AM), Flood Risk Management (FRM), Facilities and Equipment Maintenance (FEM), Inland Navigation (INAV), the Great Lakes and Ohio River Division (LRD), and the US Army Engineer Research and Development Center (ERDC). Instead of investigating the entire OCA process, the research sponsor focused the effort on the FRM business line. Many of the specific findings are FRM-centric but are illustrative of the challenges that exist across business lines. These interviews and data sources revealed a well-defined picture of the current OCA process and helped build a stakeholder-defined vision of what the OCA process could be. The researchers then documented the functional requirements to achieve the vision in a strategic roadmap and developed a project management plan for Fiscal Year (FY) 21-23 to make the first steps toward realizing the OCA to-be state. The general flow of the process is depicted in Figure 1. 
Figure 1. OCA study approach.

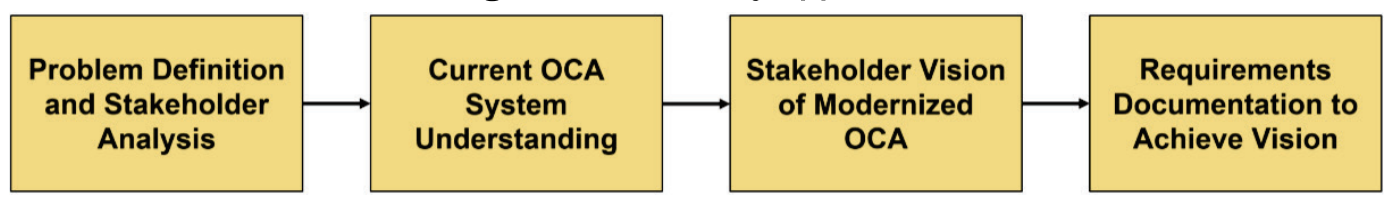

The study was further scoped through an agreed-upon set of constraints, limitations, and assumptions.

Constraints. A restriction imposed by the study sponsor that limit the study team's options in conducting the study.

- This study began in April 1, 2020, and had to be complete by September 30, 2020.

- Sponsors focused initial efforts on assets associated with FRM.

- Any recommendations made had to be solutions-agnostic.

Limitations. Factors that impact the study team's ability to fully investigate the study issues.

- Because of COVID-19, travel was restricted.

- Access to condition data was limited to data pulled from the OCA reporting system.

Assumptions. A statement related to the study that is taken as true in the absence of facts, often to accommodate a limitation.

- Focusing on the FRM business line would provide sufficient picture of the as-is state of the OCA process.

- Access to subject matter experts would be sufficient to develop a vision for the to-be state.

\subsection{Scope}

This special report has a three-fold purpose:

1. Describe the as-is state of the system that enables the OCA process generally and how the data generated through the process are used to inform maintenance, repair, and replacement (MR\&R) resourceallocation decisions. 
2. Envision the to-be state of the system that enables the OCA process including conducting OCAs, data strategy, determining asset risk, and scheduling and prioritizing OCAs.

3. Outline the functional requirements to achieve the OCA to-be state through a set of high-level strategic objectives for the enterprise and a more detailed description of the first work unit to begin enabling the achievement of two of these objectives.

In addition to giving a high-level description of the purpose of this document, the preceding three bullets also outline the flow of the document and map to the sequence of the study approach. First, the current OCA process is described both in terms of the how OCA data are generated and used. Second, the stakeholder-defined vision of a modernized OCA process is given. Third, the functional requirements to achieve the modernized OCA process are outlined. 


\section{OCA "as-is" State}

\subsection{OCA mechanics}

\subsubsection{Terms of reference}

Before analyzing the OCA process and its impact on resource allocation, it is helpful to explain the OCA infrastructure hierarchy and to define what is meant by "operational condition" and "assessment." Figure 2 displays the OCA infrastructure hierarchy. In this hierarchy, the highest level is called an operating project (e.g., a dam). These operating projects decompose into systems, subsystems, and finally components. OCAs are performed at the component level.

Figure 2. OCA infrastructure hierarchy.

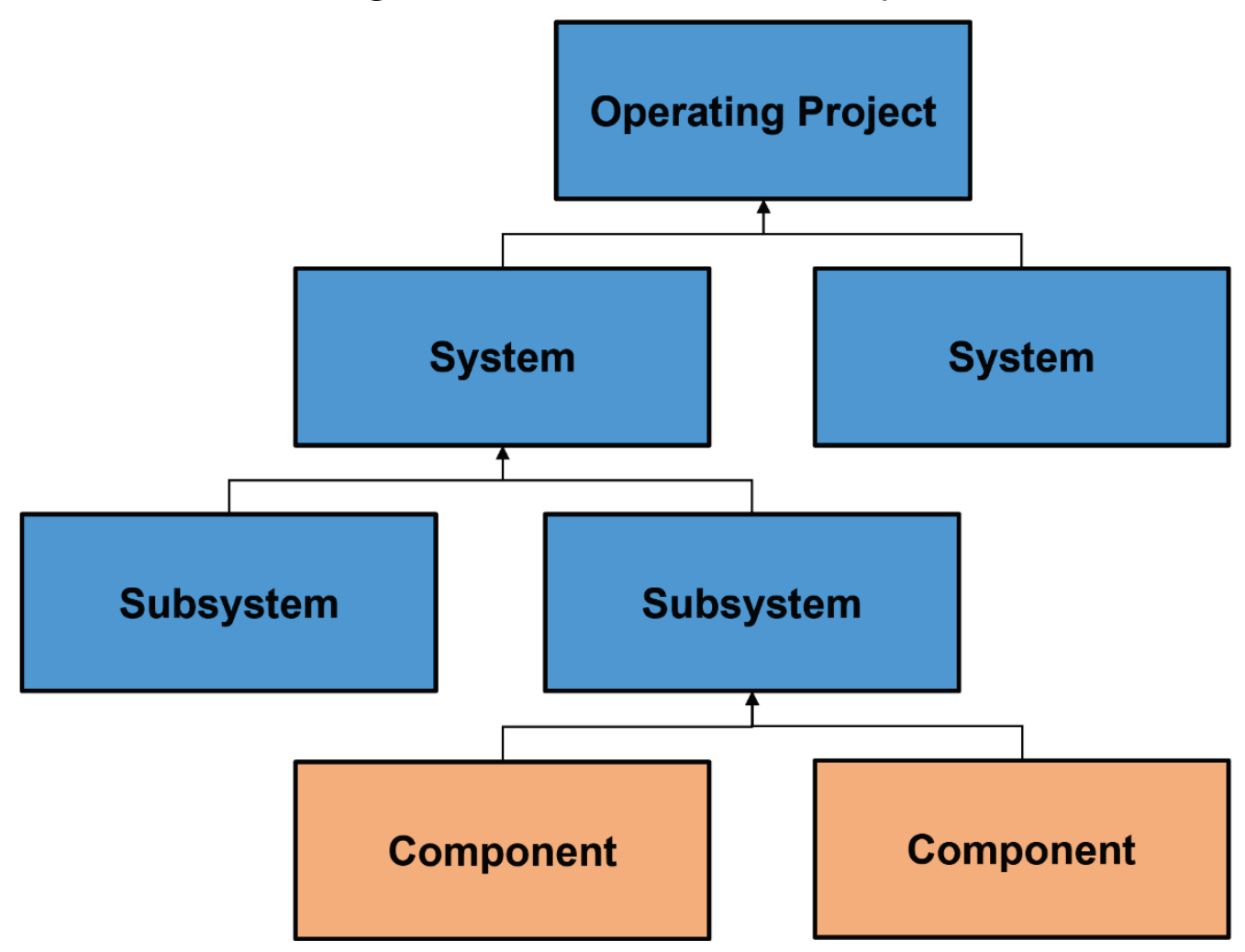

The operational condition of a component refers to (1) the "condition state, specifically, the degree of severity of an observed and/or documented deficiency" and (2) "the level or degree to which a deficiency degrades the component's performance, alters operational procedures, and/or increases its maintenance requirements." Assessment refers to "the use of existing data, as much as possible, to accurately determine the 
asset's operability and readiness." (USACE 2019) Note that although OCAs often involve visual inspection, visual inspection is not required.

\subsubsection{OCA process overview}

When a full OCA is conducted, it includes each component of a given operating project. In the FRM business line alone, there are 128,698 components, leading to assessment reliability and consistency issues. To determine condition ratings, OCA teams leverage existing data, from various sources, to justify their ratings. These data can include annual condition inspections, bridge inspections, engineering reports and analyses, FEM data, hydraulic steel structure inspections, periodic inspections, risk and reliability investigations, risk analysis evaluations, security reports, performance data, and underwater inspections. Significant variability exists in the data available for each Operating Project and the data made use of by the OCA teams. Additionally, OCA teams often perform an onsite walk-around and interview project staff. The condition ratings range from A (Excellent) to CF (Completely Failed). Table 1 displays the rating scale and the definitions for each rating (USACE 2019). 
Table 1. OCA rating scale and definitions (USACE 2019).

\begin{tabular}{|c|c|c|c|c|}
\hline \multicolumn{2}{|c|}{ Rating } & Descriptor & Definition & Notes \\
\hline A- & 9 & Excellent & $\begin{array}{l}\text { Component was recently put into service and shows no signs } \\
\text { of wear. }\end{array}$ & \multirow{4}{*}{ 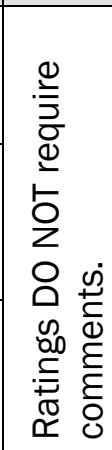 } \\
\hline B & 7 & \multirow{2}{*}{ Good } & \multirow{2}{*}{$\begin{array}{l}\text { Component performs its intended function. Any deficiencies } \\
\text { are normal wear and not actively progressing at a greater rate } \\
\text { than normal wear. }\end{array}$} & \\
\hline B- & 6 & & & \\
\hline C & 5 & \multirow{2}{*}{ Fair } & \multirow{2}{*}{$\begin{array}{l}\text { Component has a deficiency that is beginning } 1 \text { to affect its } \\
\text { performance, operational procedures, and/or maintenance } \\
\text { requirements. } \\
\text { AND/OR } \\
\text { Component is beginning to show a greater rate of change in } \\
\text { degradation that has the potential to cause a functional } \\
\text { failure. }\end{array}$} & \\
\hline C- & 4 & & & \multirow{5}{*}{ 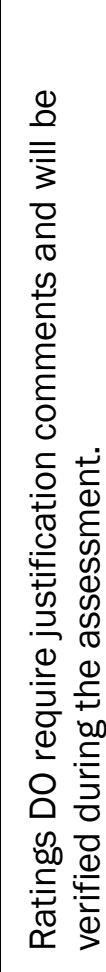 } \\
\hline D & 3 & & $\begin{array}{l}\text { Component has a deficiency that increasingly }{ }^{2} \text { or moderately } 3 \\
\text { affects its performance, operational procedure, and/or } \\
\text { maintenance requirements. }\end{array}$ & \\
\hline D- & 2 & & $\begin{array}{l}\text { AND/OR } \\
\text { Component has a clear mode of failure due to an advanced } \\
\text { state of degradation likely with an accelerating trend. }\end{array}$ & \\
\hline$F$ & 1 & Failing & $\begin{array}{l}\text { Component has a deficiency that substantially } 4 \text { affects its } \\
\text { performance, operational procedures, and/or maintenance } \\
\text { requirements and is approaching complete failure. } \\
\text { AND/OR } \\
\text { Component is clearly in the final stage of degradation trending } \\
\text { toward complete failure (imminent failure). }\end{array}$ & \\
\hline CF & 0 & $\begin{array}{l}\text { Completely } \\
\text { Failed }\end{array}$ & $\begin{array}{l}\text { Component is completely failed and does not perform its } \\
\text { intended function. } \\
\text { AND/OR } \\
\text { Component is red-tagged. }\end{array}$ & \\
\hline \multicolumn{4}{|c|}{ Minus OCA Rating Definition } & \\
\hline \multicolumn{4}{|c|}{$\begin{array}{l}\text { The minus OLCA ratings (A-, B-, C-, and D-) are for components that meet the definition of a } \\
\text { particular OCA rating but may be showing initial signs of the next lower OCA rating. }\end{array}$} & \\
\hline
\end{tabular}

Note that only ratings below a B require written comments documenting a component's deficiencies. These comments describe the deficiency's impact on operations, maintenance, and performance along with data sources used to identify the deficiency (e.g., periodic inspection report). These ratings along with supporting documentation are submitted to the Major Subordinate Command Regional Asset Manager where disputes are resolved (USACE 2019). Upon completion of that process, approved data entry personnel post the rating results to the OCA database. 


\subsubsection{Insights from OCA data}

As part of the OCA system, operating projects are decomposed into systems, and their components are tracked in a database that OCA teams update with the results of completed OCAs. During exploratory data analysis of this data set, the team found that the overwhelming majority of OCA ratings were in the " $\mathrm{B}$ " category, which corresponded with comments from stakeholders. These data also provided understanding of the full scale of the problem. As an example, Figure 3 shows how the Sardis Dam, one of 21 operating projects in the Vicksburg District, decomposes into 16 systems and 92 subsystems, with 742 components that all require an OCA. To illustrate what these layers represent, Figure 4 shows a single strand from operating project to components.

Figure 3. Sardis Dam OCA decomposition.

\begin{tabular}{|c|c|}
\hline \multicolumn{2}{|l|}{1 Operating Project } \\
\hline \multicolumn{2}{|l|}{16 Systems } \\
\hline 92 Subsystems & 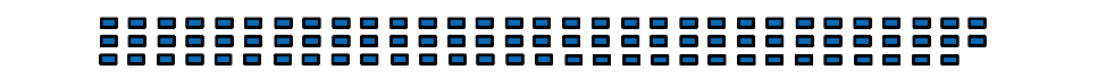 \\
\hline 742 Components & 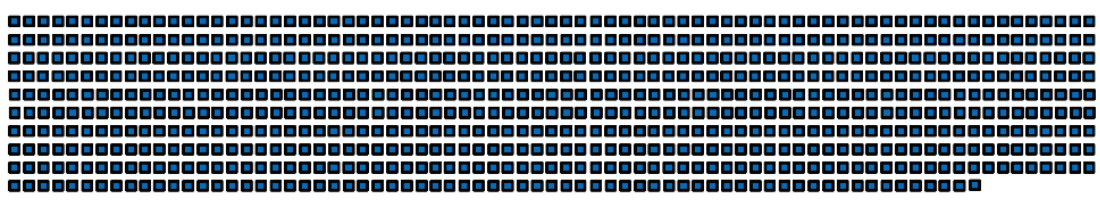 \\
\hline
\end{tabular}

Figure 4. Sardis Dam example system, subsystem, and components.

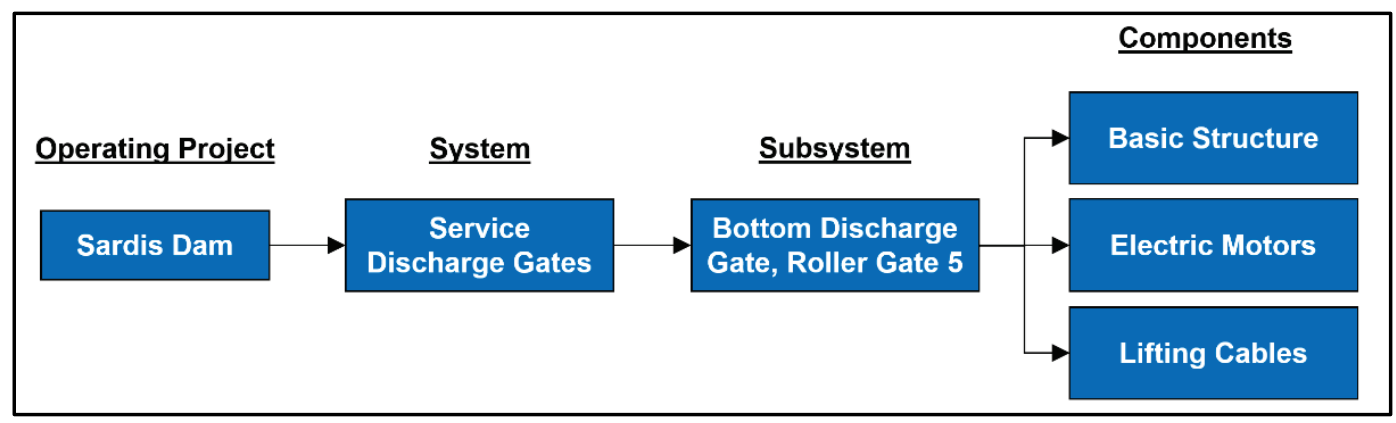




\subsection{Guiding questions}

How are operating projects currently scheduled for an OCA?

Full OCAs must be scheduled at a maximum of every 5 years. Some Major Subordinate Commands meet that requirement by doing OCAs every 5 years, but others do them more frequently. Additionally, zero components or operating projects receive scheduling priority because risk has not been determined at the operating-project level, and risk drivers have not been identified at the component level.

How is risk currently assessed and considered in the OCA process?

Risk scores have not been determined for USACE operating projects, and risk drivers have not been identified for components. Therefore, there are no relevant risk scores to inform the OCA process.

How are the results used in conjunction with risk data to inform resource decisions?

Specifically, the OCA ratings comprise the condition leg of the $5 \times 5$ relative risk matrix, which is tied to maintenance work packages and not to inherent component qualities. This is a data field in the Civil Works Integrated Funding Database, which is a budget tool used at Headquarters, USACE (HQUSACE), to fund projects through Civil Works (CW). However, this answer requires further explanation. Work packages are created across the USACE-CW enterprise to request funding for operating project MR\&R not commonly performed. When these work packages reach HQUSACE, decisions are made as to what MR\&R work packages get funded. Each work package will propose MR\&R on a certain operating project, which will contain numerous components. Additionally, each work package has a $5 \times 5$ relative risk matrix containing a condition leg and a consequence leg. The condition leg of the matrix is an $\mathrm{A}-\mathrm{F}$ rating, and OCA ratings are used to fill this condition leg. This system creates an irreconcilable mismatch in that the work package is at the project level, but the OCA ratings are at the component level, which begs the following question: "How does one fill the condition leg of the matrix?" Official guidance mandates that the dominant component's OCA rating be used, but this subjective choice leaves room for drastically different scores for the same work package as demonstrated in Figure 5 (USACE 2020). 
Figure 5. OCA impact on $\mathrm{CW}$ resource allocation.

\begin{tabular}{|c|c|c|c|c|c|c|c|}
\hline MR\&R Work Package & \multicolumn{6}{|c|}{$5 \times 5$ Relative Risk Matrix } & Civil Works Integrated Funding Database \\
\hline \multirow{6}{*}{$\begin{array}{l}\text { Component Ratings } \\
\text { Component } 1 \text { - A } \\
\text { Component } 2 \text { - } \\
\text { Component } 3 \text {-D } \\
\text { Component } 4 \text { - B } \\
\text { Component } 5 \text { - B }\end{array}$} & \multirow{6}{*}{ 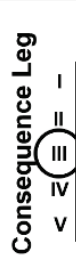 } & \multirow{2}{*}{\multicolumn{5}{|c|}{ Condition Leg }} & \multirow{6}{*}{$\begin{array}{l}\text { Work Package } x x x x \\
\text { Factor A: } x x x x \\
\text { Factor B: } x x x x \\
\text { Factor C: } x x x x \\
5 x 5 \text { RRM Score } 22 \text { or } 8 \\
\text { Factor E: } x x x x\end{array}$} \\
\hline & & $\frac{r}{1}$ & & 6 & 10 & 15 & \\
\hline & & 2 & 5 & 9 & 14 & 19 & \\
\hline & & 4 & 8 & 13 & 18 & 22 & \\
\hline & & 7 & 12 & 17 & 21 & 24 & \\
\hline & & 11 & 16 & 20 & 23 & 25 & \\
\hline
\end{tabular}

For example, if one person considers Component 1 to be the dominant component and another person considers Component 3 to the dominant component, then their resulting risk scores will be very different. If the consequence level is a III, then one work package will receive a risk score of 22 and the other a risk score of 8 despite the reality that these are identical work packages. This difference in risk scores has implications on whether or not this work package will get funded. 


\section{OCA "to-be" State}

Informed by and understanding of the as-is state and the objectives of the system and guided by stakeholder input, the team developed a vision for the to-be state of the system.

Vision: A consistent view of asset condition and risk across the enterprise

This vision requires transparency, consistency, and traceability.

Transparency means that asset data are systematically collected and maintained across the enterprise to inform a common operating picture for USACE decision makers and data-driven resource decisions to mitigate risk. Consistency means that common asset data are made available to OCA teams to enable consistent OCA processes across the enterprise.

Traceability means that asset risk and resource decisions can be traced back to component risk and condition assessments informed by the OCA process.

For the OCA process to more effectively provide a current assessment of asset condition, four major work areas need to be addressed to implement or improve the functions that comprise the OCA system: (1) providing data access, (2) conducting assessments, (3) determining asset risk, and (4) prioritizing and scheduling. The columns in Figure 6 map to these work areas.

Figure 6. High-level OCA system functional decomposition.

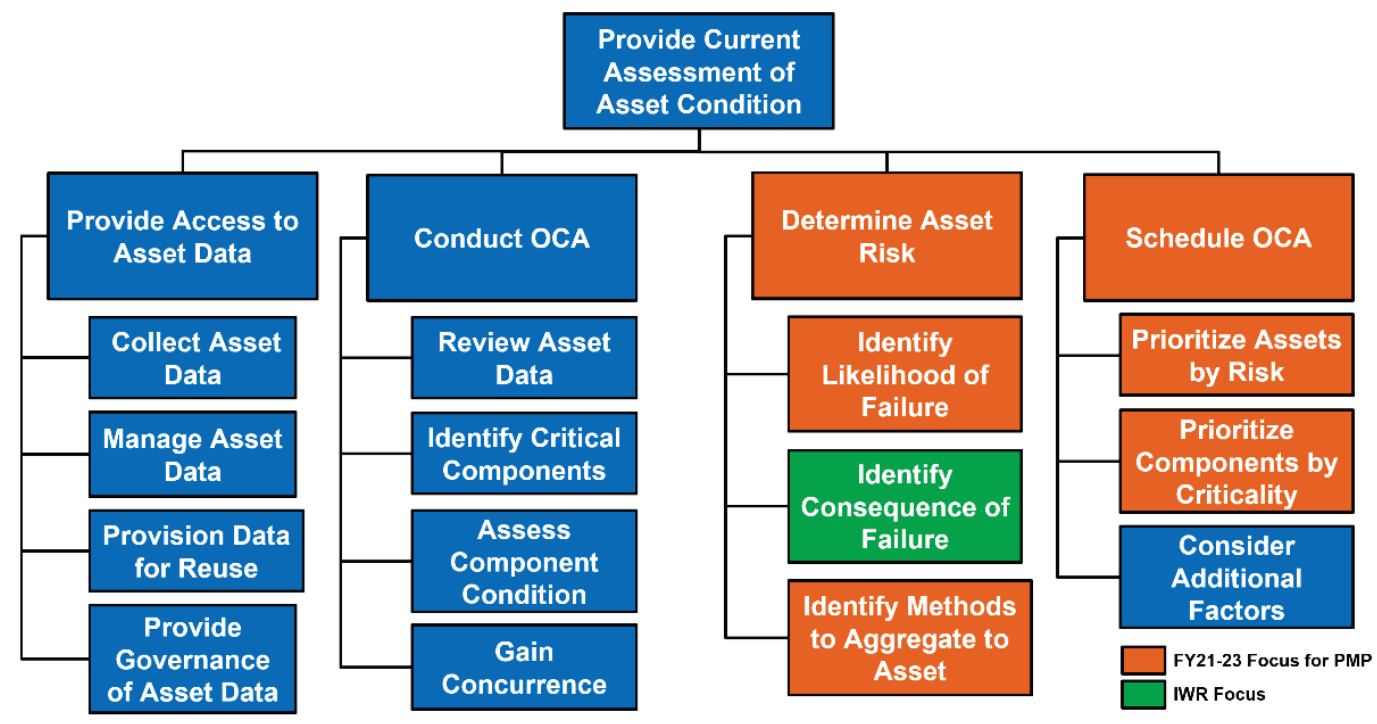


The columns on the left represent functions that require operational changes to the AM program. "Provide Access to Asset Data" speaks to an enterprise-level data strategy in which asset data are highly valued as an enterprise commodity. Those data are systematically collected, managed, provisioned for reuse, and governed. "Conduct OCA" speaks to the manner in which OCAs are conducted. This means that assessors have a consistent, intuitive picture of all asset data and knowledge of the critical components that contribute to flood risk. The technologies and procedures used in assessing component conditions should be reliable, and the component condition ratings should receive concurrence from operating project staff, regional asset managers, and other pertinent personnel.

The columns on the right require research to develop methods of determining asset risk and a framework for scheduling OCAs based on risk. "Determine Asset Risk" speaks to the need to understand the risk associated with the various components of each operating project. This requires data on the likelihood and consequence of operating project failure. Last, "Schedule OCA" speaks to a prioritized scheduling framework. Instead of interval-based scheduling, AM could develop a scheduling framework in which assets and components that contribute to more risk receive higher scheduling priority.

A further decomposition of these functions would lead to the identification of measures of effectiveness for each. This would inform an assessment process to assist OCA operations in measuring progress as changes are implemented. The next section provides greater definition of the strategic objectives and outlines, at a high level, how the researchers, in conjunction with a team from the Institute for Water Resources (IWR), plan to develop a scalable methodology to determine asset risk across the AM enterprise and then use that risk data to develop an OCA prioritization and scheduling framework. 


\section{Future OCA Functional Requirements}

\subsection{Strategic objectives to achieve modernized OCA}

To achieve the aforementioned vision of a transparent, consistent, and traceable risk-based OCA system, the following four strategic objectives must be addressed:

Provide Access to Asset Data. The asset management community must collect, manage, provision for re-use, and provide governance over authoritative data describing assets, and their current status, within the portfolio to provide stakeholders and decision makers with a single consistent repository of data to inform analysis and subsequent resourcing decisions.

Modernize Conduct of OCA. As part of the data collection process, the asset management community must modernize the manner in which OCAs are conducted to systematically make better use of available data and to ensure that the OCA process generates objective, high-quality data to inform risk and support decision makers.

Determine Asset Risk. The asset management community must develop an understanding of the relative importance of each asset, and their critical components, to the performance of the system and the likelihood that the asset will perform as expected in its current condition.

Develop OCA Prioritization and Scheduling Framework. The asset management community must develop a risk-based prioritization and scheduling framework that enables resources and OCAs to be focused on the greatest sources of risk to the enterprise.

\subsection{Determining operating project risk, FY21-23}

The purpose of FY21-23 work is to develop an enterprise framework for risk-based prioritization of OCA. Currently, OCAs are conducted each year without a risk-based prioritization method resulting in the expenditure of resources to assess assets that pose no risk to the enterprise. In particular, this work is intended to help decision makers understand which FRM operating project components require an OCA based on their contribution 
to overall risk and current component condition. To determine risk, likelihood of failure data and consequence data are required.

Risk = (consequence $\mid$ hazard) $\mathrm{x}$ (likelihood of failure $\mid$ component condition)

The researchers will conduct a literature review and elicit feedback from operating project staff to develop a methodology to determine the operating project-level likelihood of failure based on the likelihood of failure of the components that make up the operating project as is demonstrated in Figure 7.

Figure 7. Determining likelihood of failure based on component condition.

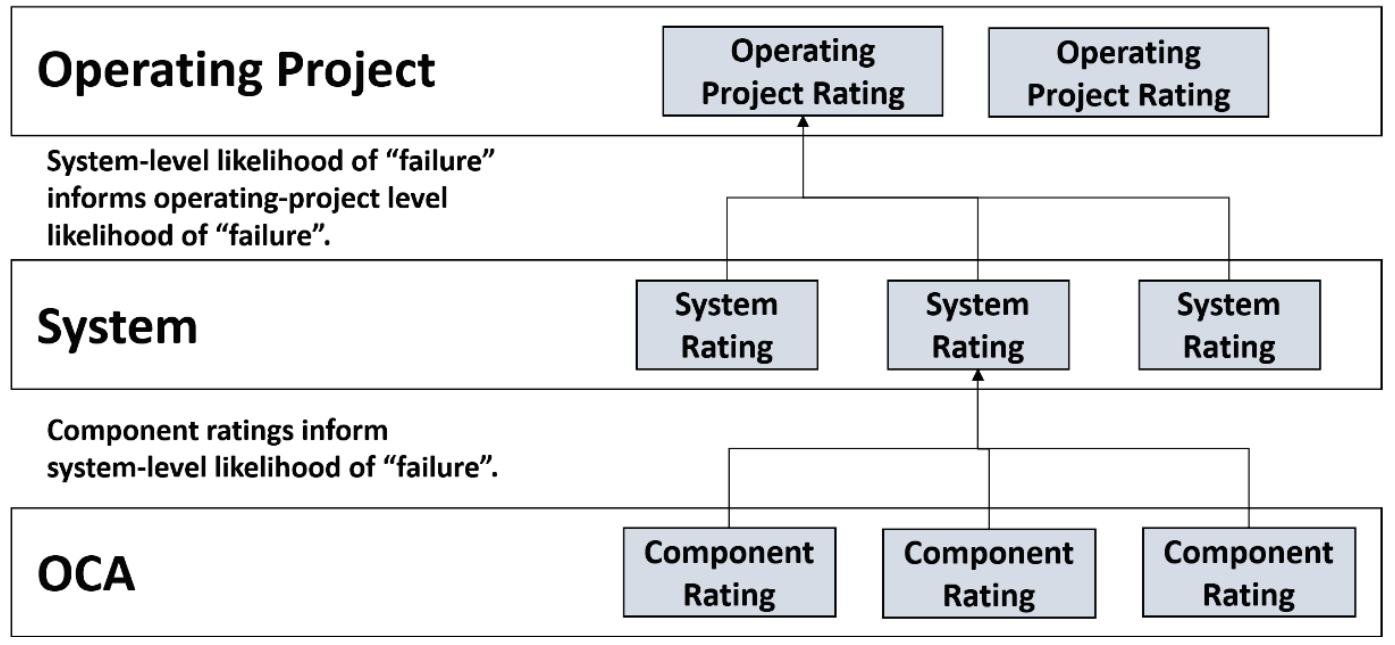

The team at IWR is modeling the watershed-level consequences of an operating project failing to perform at full operating capability at the watershed level because these operating projects work as a part of a larger FRM system within a given watershed. The systems that comprise operating projects with the most direct impact on the functioning of the watershed FRM system are those that impact the flow of water - gates. Modeling the FRM system performance in the context of the watershed in which it functions can provide insight into the contribution of each gate to the overall FRM system's ability to control the flow of water in the watershed - the consequences - under various environmental conditions. The performance of each gate as a function of the OCA-informed condition of its components will be modeled to determine the probability that the gate will function as intended. Having consequence data at the gate level and likelihood of failure data at the gate level enables the determination of risk at the gate level. The collaboration of these two modeling efforts to produce gate-level risk is demonstrated in Figure 8. A methodology will be 
developed to aggregate gate-level risk to the operating-project level. With a greater understanding of component risk drivers and operating projectlevel risk, the researchers will develop a methodology to prioritize the conduct of OCAs.

Figure 8. Determining FRM risk.

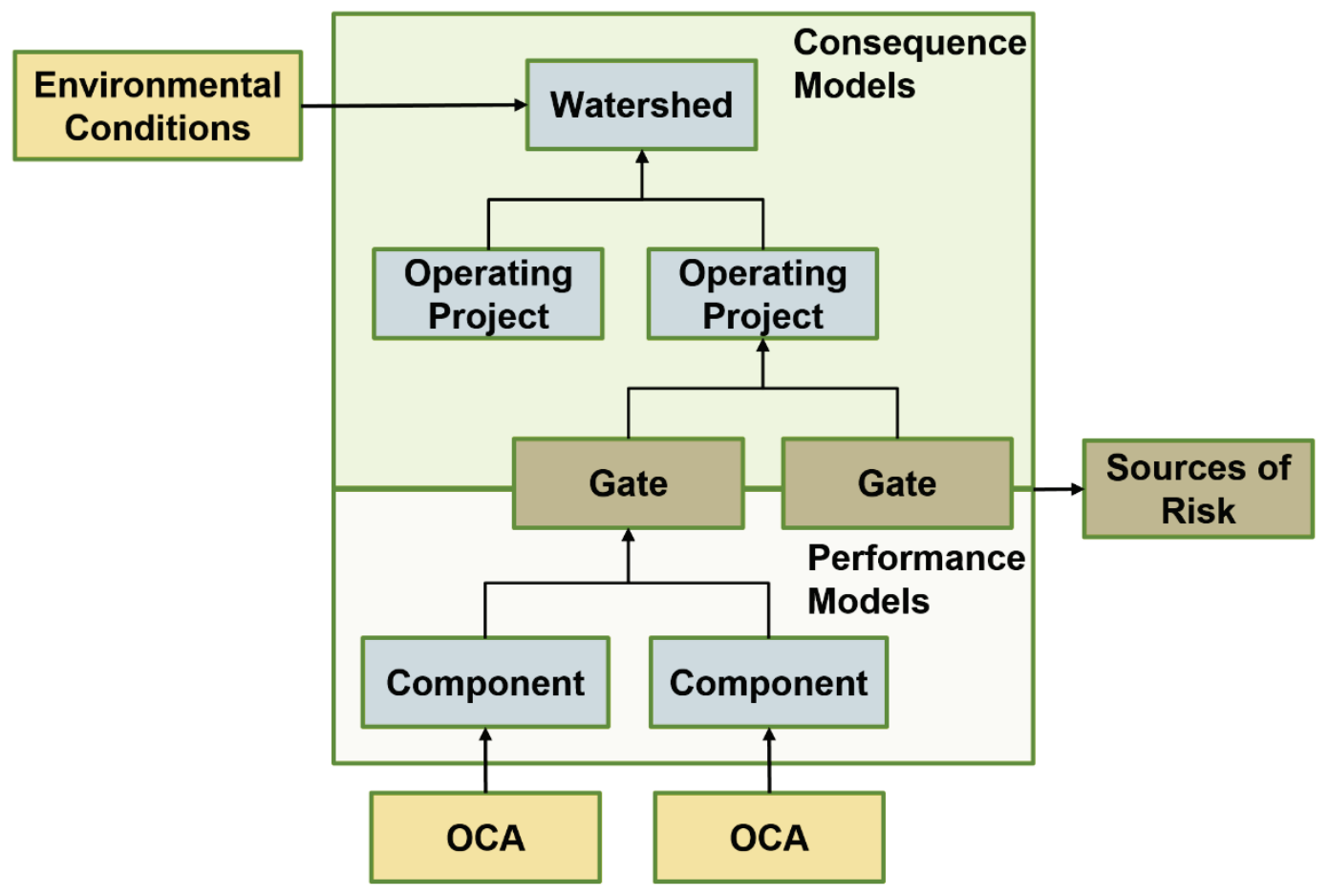




\section{Conclusions}

The USACE water resource assets impact the daily lives of American citizens, and these assets are in decline. Although the OCA system provides a defined process by which these assets are assessed, the process lacks consistency leading to unreliable condition ratings. These condition ratings then factor into a subjective work package proposal process used to fund CW MR\&R across the enterprise. The findings in this study confirm the USACE position that the system needs modernization. The vision of a modernized OCA is a consistent view of asset condition and risk across the enterprise. To achieve this vision of a modernized and improved OCA system, four major work areas need to be addressed: (1) providing data access, (2) conduct of assessments, (3) determining asset risk, and (4) prioritization and scheduling. With an initial focus on the FRM business line, the next step is to develop a scalable and generalizable methodology to determine operating project probability of failure using componentlevel OCA condition ratings. Combining this probability failure data with the IWR consequence data will provide FRM with meaningful risk data, enabling prioritized OCA scheduling and more effective CW MR\&R resource allocation.

While the determination of risk scores will greatly improve the utility of OCA data, more work is needed to improve the OCA process. To ensure that the first objective, providing access to asset data, is attained, it is recommended that the USACE AM program develop an enterprise-level data strategy that provides a vision for how the organization will (1) allow users to identify the existence of data; (2) collect and store data to facilitate use, shared access, and processing; (3) provision data for reuse and sharing and provide rules and guidelines for data access at scale; (4) process data from disparate systems to provide a consistent data view; and (5) develop data policies to govern how the organization will capture, manage, and use information for disparate sources (Klingensmith and Alt 2020).

In support of the second objective, conduct OCA, it is recommended that USACE identify existing initiatives within USACE that collect data from mechanisms not traditionally used to inform operating-project or component status (such as sensors, inspections, maintenance, or testing). The data generated by these sensors possess the potential to inform component probability-of-failure estimates. Last, inconsistent human 
actions, such as visual inspections and application of testing and monitoring equipment, result in inconsistent and unreliable condition assessments. This variability can include inconsistent procedures, inaccurate data interpretation, improper equipment calibration, and lack of experience. It is recommended that research be conducted to understand these human factors and how they influence the OCA process ${ }^{1}$.

${ }^{1}$ Sauser, P. Unpublished. Statement of Need: Reliable Inspection and Monitoring Techniques for Hydraulic Structures. 


\section{References}

Klingensmith, K., and J. Alt. 2020. "A Systems Architecting and Engineering Approach to Creating an Enterprise Data Strategy." The ITEA Journal of Test and Evaluation 44: $27-36$.

USACE (US Army Corps of Engineers). 2019. US Army Corps of Engineers Policy for Operational Condition Assessments of USACE Assets. Engineer Circular No. 112-218. https://www.publications.usace.army.mil/Portals/76/Users/182/86/2486/EC-11-2218.pdf?ver=2019-09-04-162858-440

USACE. 2020. Civil Works Direct Program Development Policy Guidance. Engineer Circular No. 11-2-222. Washington, DC: Department of the Army, US Army Corps of Engineers. 


\section{Appendix A: Interviews}

Table 2. The stakeholder interviews that informed the "as-is" and "to-be" states.

\begin{tabular}{|c|c|c|}
\hline Organization & People & Date \\
\hline $\begin{array}{c}\text { AM and ERDC- } \\
\text { Coastal and } \\
\text { Hydraulics } \\
\text { Laboratory (CHL) }\end{array}$ & $\begin{array}{c}\text { Peter Dodgion (AM), Chris Westbrook (AM), } \\
\text { Matt Smith (ERDC-CHL) }\end{array}$ & $05 / 20 / 2020$ \\
\hline $\begin{array}{c}\text { ERDC-Information } \\
\text { Technology } \\
\text { Laboratory }\end{array}$ & James Stinson & $05 / 27 / 2020$ \\
\hline AM & Joe Dziuk & $05 / 27 / 2020$ \\
\hline INAV & Andy Harkness & $05 / 28 / 2020$ \\
\hline LRD & Dan Cox & $06 / 30 / 2020$ \\
\hline FRM & Lisa Kiefel and Jeff Jensen & $06 / 30 / 2020$ \\
\hline FEM & Lund, Kerry Brink, Michael Brehm, & $07 / 16 / 2020$ \\
\hline LRD & Sharon Ramsey & $07 / 17 / 2020$ \\
\hline ERDC-CHL & Dan Cox & $07 / 24 / 2020$ \\
\hline FEM & Lisa Lund & $08 / 05 / 2020$ \\
\hline
\end{tabular}




\section{Appendix B: Tools and Data Sources}

Data Sources

- FRM OCA Data

- FRM FEM Maintenance Data

- FRM Fault Trees (2017)

- National FRM OCA Component List

- National INAV Component List

FRM Operational Risk Assessment (ORA) Tool Resources

- Past Attempts at an FRM ORA Tool

- Conemaugh Dam

- John W. Flanagan Dam

- Senecaville Dam

- FAQs on FRM ORA

- Notional FRM ORA Tool Slides

Other Resources

- OCA-FRM Integration Plan PMP

- INAV ORA Risk Calculation Walkthrough Files

- Sample INAV ORA Budget Workbook, Pittsburgh District 


\section{Acronyms and Abbreviations}

\begin{tabular}{ll} 
AM & Asset Management \\
CW & Civil Works \\
ERDC & Coastal and Hydraulics Laboratory \\
FEM & US Army Engineer Research and Development Center \\
FRM & Facilities and Equipment Maintenance \\
FY & Flood Risk Management \\
HQUSACE & Fiscal Year \\
INAV & Headquarters, US Army Corps of Engineers \\
IWR & Inland Navigation \\
LRD & Institute for Water Resources \\
MR\&R & Great Lakes and Ohio River Division \\
OCA & maintenance, repair, and replacement \\
ORA & Operational Conditional Assessment \\
USACE & Operational Risk Assessment \\
\hline
\end{tabular}




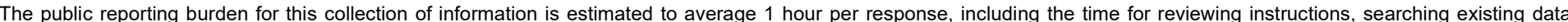

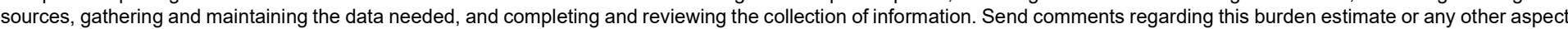

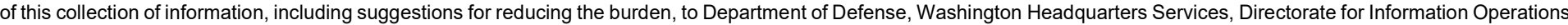

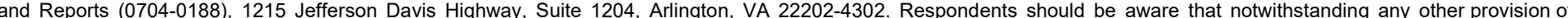
law, no person shall be subject to any penalty for failing to comply with a collection of information if it does not display a currently valid OMB control number. PLEASE DO NOT RETURN YOUR FORM TO THE ABOVE ADDRESS.

\begin{tabular}{l|l|l}
$\begin{array}{l}\text { 1. REPORT DATE } \\
\text { March } 2021\end{array}$ & $\begin{array}{l}\text { 2. REPORT TYPE } \\
\text { Final Report }\end{array}$ & 3. DATES COVERED (From - To)
\end{tabular}

\section{TITLE AND SUBTITLE}

Investigating the USACE Operational Condition Assessment Process Current and Future 5a. CONTRACT NUMBER

5b. GRANT NUMBER

5c. PROGRAM ELEMENT NUMBER

6. AUTHOR(S)

Willie H. Brown and Jonathan K. Alt

\section{5d. PROJECT NUMBER}

5e. TASK NUMBER

5f. WORK UNIT NUMBER

8. PERFORMING ORGANIZATION REPORT NUMBER

ERDC/ITL SR-21-1

10. SPONSOR/MONITOR'S ACRONYM(S) NavSys

11. SPONSOR/MONITOR'S REPORT NUMBER(S)

Vicksburg, MS 39180-6199

\section{DISTRIBUTION/AVAILABILITY STATEMENT}

Approved for public release; distribution is unlimited.

\section{SUPPLEMENTARY NOTES}

Funding Account Code U4371811; AMSCO Code 031391

\section{ABSTRACT}

The US Army Corps of Engineers operates, maintains, and manages more than $\$ 232$ billion worth of the Nation's water resource infrastructure and relies on the Operational Condition Assessment (OCA) process to determine the condition of the assets and their components. The sheer number of components, all of equal OCA scheduling priority, creates challenges in ensuring that assessments are conducted in a timely manner and that data generated are of sufficient quality to inform resource allocation decisions. This research applied methods from systems design to determine the OCA system "as-is" state and create a stakeholder-informed vision of a "to-be" state that addresses current system challenges. To meet its objective of providing current assessments of asset condition, the OCA system must provide four high-level functions: provide access to asset data, conduct assessments, determine asset risk, and prioritize and schedule assessments. The development of capabilities to provide these functions will facilitate the achievement of the OCA system to-be vision: a consistent view of asset condition and risk across the enterprise.

\section{SUBJECT TERMS}

Asset allocation, Civil engineering_Planning, Decision making, Engineering-Management, Infrastructure (Economics), Operations research, Risk assessment

\section{SECURITY CLASSIFICATION OF:}

\begin{tabular}{|l|c|l|}
\hline a. REPORT & b. ABSTRACT & c. THIS PAGE \\
Unclassified & Unclassified & Unclassified \\
& & \\
\hline
\end{tabular}

17. LIMITATION OF ABSTRACT

SAR
18. NUMBER 1 OF PAGES

29 19a. NAME OF RESPONSIBLE PERSON Willie H. Brown

19b. TELEPHONE NUMBER (Include area code) 601-634-4199 